\title{
What happens when an anti-realist and a realist read each other's book?
}

\section{K. Brad Wray ${ }^{1} \cdot$ Luciano Boschiero $^{2}$}

Published online: 14 February 2019

(C) Springer Nature B.V. 2019

In addition to regular reviews, book notes, essay reviews, and symposia, Metascience also publishes anniversary pieces, reflecting on the importance of a particular book in one of our fields, history of science, philosophy of science, and science studies. These reviews are commissioned by the journal editors and are often written by scholars who have a particularly insightful perspective on the piece under review. This issue includes two such pieces, one on Bas van Fraassen's Laws and Symmetry, originally published in 1989, and one on Stathis Psillos' Scientific Realism: How Science Tracks Truth, originally published in 1999. The books are celebrating their 30th and 20th year in print, respectively. Both books have played a significant role in the realism/anti-realism debate over the last few decades. Van Fraassen is one of the key contemporary proponents of anti-realism, and Laws and Symmetry contains a number of his critical arguments against realism, most importantly against realist conceptions of laws of nature. But the book is filled with much more, including his influential attack on inference to the best explanation as a rule of inference. Psillos' book is one of the few sophisticated and comprehensive surveys of the realism/ anti-realism debate and has thus become a standard textbook of sorts for those interested in the debate. But Scientific Realism is far more than a textbook. In it, Psillos advances his own realist position, a form of what has come to be called selective realism, one of the most influential realist positions in the contemporary debate. These two books would be on any reading list of the ten most important books to read for anyone wanting to engage in the debate. And their importance does not seem to be waning.

The editors would like to confess to being a bit sly in arranging these anniversary reviews. Unbeknownst to the authors of the books, we simultaneously invited van Frasssen, an anti-realist, to review Psillos' book and Psillos, a realist, to review van

K. Brad Wray

kbwray@css.au.dk

Luciano Boschiero

1.boschiero@campion.edu.au

1 Centre for Science Studies, Aarhus University, Aarhus, Denmark

2 Campion College, Sydney, Australia 
Fraassen's book. Those who are interested in this debate will find the two reviews a pleasure to read, as both authors step back from their own position and provide a thoughtful reflection on their adversary's contribution to the debate.

In addition to these two pieces, this issue of Metascience contains the usual mix of thoughtful reviews on a wide range of topics, including Thomas Kuhn's philosophy, inductive risk, sex with robots, the periodic table of elements, and the influence of Arabic sources on European science.

Publisher's Note Springer Nature remains neutral with regard to jurisdictional claims in published maps and institutional affiliations. 